УДК 8

DOI $10.21661 /$ r-467968

\title{
Р.Б. Бекенова
}

\section{ИСПОЛЬЗОВАНИЕ ТЕОРИИ ВАЛЕНТНОСТИ И АППАРАТА ПАДЕЖНОЙ ГРАММАТИКИ ДЛЯ ХАРАКТЕРИСТИКИ СЕМАНТИКИ ПРОИЗВОДНОГО СЛОВА}

Аннотация: в статье рассматривается понятие валентности как явления, находящцегося на пересечении синтаксиса и лексической семантики. В работе также представлены виды валентности, направления, по которым рассматривается теория валентности и ее параллель с падежной грамматикой. Представленная работа ставит перед собой задачу разобраться в причинах, по которым производное слово может являться отражением глубинных падежных значений.

Ключевые слова: валентность, актанты, сочетаемость, лексическая сочетаемость, синтаксическая сочетаемость, семантика, семантическая структура, падежная грамматика, падежное значение, глагол, производное слово, пропозищчия.

\section{R.B. Bekenova}

\section{THE USE OF VALENCY GRAMMAR AND APPARATUS}

\section{OF CASE GRAMMAR TO CHARACTERIZE THE SEMANTICS OF A DERIVATIVE WORD}

Abstract: the article discusses the valence concept as a phenomenon at an intersection of syntax and lexical semantics. The author also provides the types of valence and directions that help to study the valence theory in parallel with case grammar. The study aims to look into the reasons why the derivative word may be the reflection of underlying grammatical case meanings. 
Keywords: valence, actants, compatibility, lexical compatibility, syntactical compatibility, semantics, semantic structure, case grammar, case value, verb, derived word, proposition.

Валентности, представляющей собой точку пересечения синтаксиса и лексической семантики, уделяется огромное внимание в современных лингвистических исследованиях.

В отечественной лингвистике теория валентности широко освещается в работах С.Д. Кацнельсона, Б.А. Абрамова, Ю.Д. Апресяна, М.Д. Степановой, Г.Г. Сильницкого, О.И. Москальской, С.М. Кибардиной и др. Данная проблема активно разрабатывается немецкими лингвистами, типологами США.

Понятие валентности выделено и обосновано французским лингвистом Л. Теньером. Глагол и подчиняющиеся ему члены сравнивались им с пьесой, вербальный узел которой включает какой-либо процесс с наиболее встречающимися действующими лицами и типичные обстоятельства. В зависимости от выполняемой функции выделяется три участника: тот, кто совершает действие (субъект); тот, кто испытывает на себе действие (объект); тот, в пользу которого или в ущерб которому осуществляется действие (адресат). Валентность в этом плане понимается как число участников, которыми способен управлять глагол, т.е. потенциальная сочетаемость глагола с подлежащим и дополнением [9].

С точки зрения современных лингвистов, валентность представляет собой как способность той или иной части речи создавать вокруг себя открытые позиции, которые могут быть заполнены облигаторными или факультативными актантами.

Различают следующие типы валентности: одноместные и многоместные, активные и пассивные, центробежные и центростремительные, внутренние и внешние, обязательные и факультативные, грамматические и лексические, лексические и синтаксические, категориальные и индивидуальные, содержательные и формальные и др.

Сочетаемостные свойства слова обусловлены рядом причин грамматического и лексического характера. 
Так, при анализе валентностей глагола учитываются следующие факторы: количество актантов, их частеречный статус, принадлежность к определённому семантическому классу, семантические роли актантов (одушевлённые / неодушевлённые, конкретные / абстрактные, обязательные / факультативные); количество мест, возможных при глаголе, и признаки аргументов, способных замещать эти места; функции актантов (субъект, объект и т. д.).

Понятия валентность и сочетаемость употребляются нами как синонимичные, однако в ряде работ они разграничиваются. Так, сочетаемость рассматривается как реализованная валентность, а валентность - как потенциальная сочетаемость элементов одного языкового уровня. Под сочетаемостью понимается свойство слова реализовать в речи свои синтагматические связи в виде словосочетания [7, с. 46], это парадигматика его синтагматических свойств, упорядоченная совокупность сочетающихся с ним слов [2, с. 157].

Сочетаемость слова отражает его валентность: при употреблении производного в предложении обозначаемая им валентность диагностируется сочетаемостью, при этом сочетаемость производного в разных значениях не совпадает, а нередко и просто дополнительна, ср. словосочетание старика знобит от холода и знобкий для старика ветер, где в последнем сочетаемость является дополнительной [1, с. 24].

Сочетаемость слов относится одновременно к области грамматики и лексикологии, т.к. в этом понятии переплетаются грамматические и лексические значения, в зависимости от чего принято выделять два типа сочетаемости - лексическую и синтаксическую. Если синтаксическая сочетаемость связана с использованием слова в определённых конструкциях и является общим фактором, определяющим лексические связи слов данной части речи, то лексическая сочетаемость определяет способность конкретного слова сочетаться с другими словами, проявлять избирательность в соединении с ними. Синтаксическая сочетаемость отражает принадлежность к тому или иному грамматическому разряду, в то время как лексическая сочетаемость обусловлена его индивидуальными семантическими свойствами [3, с. 166]. 
Н.3. Котелова отмечает такие особенности лексической сочетаемости, как неустойчивость системы, неотчётливость проявления узуса и уязвимость нормы, что затрудняет выявление системных, постоянных характеристик этих свойств слова [2, с. 48]. Лексическая и синтаксическая валентность, с одной стороны, автономны относительно друг друга, а с другой - тесно взаимосвязаны и дополняют друг друга, т.к. лексическая валентность в определённой степени опирается на синтаксическую.

Существует два направления теории валентности: вербоцентрическое и субъектно-предикатное. Если для первого этапа развития теории валентности характерны вербоцентрическое направление и внимание к её количественной стороне, то в дальнейшем происходит углубленное изучение её лексико-семантического уровня и валентностных особенностей разных частей речи [8]. Важным этапом явилось выделение содержательной, глубинной валентности, которая противопоставлена формальной валентности.

Содержательная валентность отражает понятийный уровень, это явление глубинного семантического плана, пропозиции. Формальная валентность проявляется в конкретных языковых значениях и выражена явно. Семантическая структура предложения может быть передана в скрытом виде в поверхностной структуре, т.к. внешние формы связи лишь частично отражают их внутренние отношения, которые определяются валентностями предиката и его аргументами $[6$, c. 93].

Теория валентности соприкасается с падежной грамматикой, создателем которой является Ч. Филлмор [10]. Падежи в его понимании - это функции, формирующие глубинные семантические структуры. В глубинных падежах исчислены семантические роли актантов относительно предикатов. Они не совпадают с грамматическими падежами и членами предложения, т.е. единицами поверхностной структуры.

В рамках падежной грамматики глагол рассматривается как источник, объединяющий семантические роли актантов в единое целое. Одна из важнейших задач падежной грамматики заключается в описании механизмов, 
обеспечивающих выбор поверхностных падежей для выражения семантических функций, т.е. процессов перехода от глубинных структур к их поверхностным реализациям [4, с. 87$]$.

Исходным пунктом падежной грамматики считается теория Л. Теньера, в которой выделено понятие актантов как зависимых от глагола «сопроводителей действия». Однако если Теньер, рассматривая предложение как маленькую драму со своим действием, действующими лицами (актантами) и обстоятельствами (сирконстантами), трактовал актанты и сирконстанты как формальные категории синтаксиса, то Ч. Филлмор применяет свою модель для объяснения содержания предложения [4, с. 73]. Следовательно, падежная грамматика является шагом вперёд по сравнению с теорией валентности, поскольку является более «семантической».

Как отмечает Ч. Филлмор, «в рамках грамматической теории понятие глубинных падежей может оцениваться с точки зрения его значимости для теории грамматических уровней, для описания валентностей и коллокаций, а также для общей теории функций составляющих предложений» [11, с. 497].

По мнению Е.С. Кубряковой, словообразование играет особую роль в выражении падежных значений. Нет ни одной категории падежной грамматики, которая не имела бы аналогий в словообразовательных системах [5, с. 44].

В поверхностной структуре производного слова фиксируются лишь отдельные члены пропозиции. Определённый тип отношений между ономасиологическим базисом и ономасиологическим признаком выражается мотивирующей основой и формантом. Семантические роли участников сцены, которые содержатся в пропозиции, могут найти как явное, так и скрытое проявление в производном слове.

Актантная структура слов обусловлена степенью семантической наполненности. Чем меньше слово наполнено семантически, тем больше валентностей, а значит, актантов у него будет [1, с. 24].

Итак, производные слова являются отражением глубинных падежных значений, присутствующих в них в явном и скрытом виде. Изучение суждений, 
лежащих в основе производного слова, позволяет выявить их ролевую структуру, т.е. семантические функции каждого компонента пропозиции, прежде всего субъекта и объекта.

\section{Список литературы}

1. Артюхова С.В. Словообразовательный потенциал глаголов с семой «эмоция» в современном русском языке: Дис. ... канд. филол. наук. - Махачкала, 2005.

2. Котелова Н.З. Значение слова и его сочетаемость. - Л.: Наука,1975.

3. Кубрякова Е.С. Типы языковых значений. Семантика производного слова. - М.: Наука, 1981.

4. Кубрякова Е.С. Падежная грамматика. - Современные зарубежные грамматические теории. Сб. научно-аналитичесих обзоров / Е.С. Кубрякова, Ю.Г. Панкрац. - М., 1985.

5. Кубрякова Е.С. Категории падежной грамматики и их роль в сравнительно-типологическом изучении словообразовательных систем славянских языков. - В кн. Сопоставительное изучение словообразования славянских языков. М.: Наука, 1987.

6. Маслова Н.А. Семантика и синтаксис производных имен существительных современного немецкого языка. - Казань, 1985.

7. Медникова Э.М. Значение слова и методы его описания. - М.: Высшая шк., 1974.

8. Степанова М.Д. Теория валентности и валентностный анализ (на материале совр. Немецкого языка). - М., 1973.

9. Теньер Л. Основы структурного синтаксиса. - М.: Прогресс, 1988.

10. Филлмор Г. Дело о падеже: Кн.: Новое в зарубежной лингвистике. - М., 1981. - Вып. 10.

11. Филлмор Г. Основные проблемы лексической семантики. - В кн.: Новое в зарубежной лингвистике. - М.: Радуга, 1983. - Вып. 12. 


\section{References}

1. Artiukhova, S. V. (2005). Slovoobrazovatel'nyi potentsial glagolov s semoi "emotsiia" v sovremennom russkom iazyke: Dis. Makhachkala

2. Kotelova, N. Z. (1975). Znachenie slova i ego sochetaemost'. L.: Nauka

3. Kubriakova, E. S. (1981). Tipy iazykovykh znachenii. Semantika proizvodnogo slova. M.: Nauka

4. Kubriakova, E. S., \& Pankrats, Iu. G. (1985). Padezhnaia grammatika. M.

5. Kubriakova, E. S. (1987). Kategorii padezhnoi grammatiki i ikh rol' v sravnitel'no-tipologicheskom izuchenii slovoobrazovatel'nykh sistem slavianskikh iazykov. M.: Nauka

6. Maslova, N. A. (1985). Semantika i sintaksis proizvodnykh imen sushchestvitel'nykh sovremennogo nemetskogo iazyka. Kazan'

7. Mednikova, E. M. (1974). Znachenie slova i metody ego opisaniia. M.: Vysshaia shk.

8. Stepanova, M. D. (1973). Teoriia valentnosti i valentnostnyi analiz (na materiale sovr. Nemetskogo iazyka). M.

9. Ten'er, L. (1988). Osnovy strukturnogo sintaksisa. M.: Progress

10. Fillmor, G. (1981). Delo o padezhe: Kn.: Novoe v zarubezhnoi lingvistike. M. Vyp. 10.

11. Fillmor, G. (1983). Osnovnye problemy leksicheskoi semantiki. M.: Raduga. Vyp. 12

Бекенова Райхан Булатовна - сениор-лектор, преподаватель кафедры гуманитарных дисциплин АО «Казахстанско-Британский технический университет», Республика Казахстан, Алматы.

Bekenova Raikhan Bulatovna - senior lecturer of the Humanities Department at Kazakh British Technical University, Republic of Kazakhstan, Almaty. 